\title{
A modified empirical criterion for strength of transversely anisotropic rocks with metamorphic origin \\ Omid Saeidi $^{1^{*},}$ Rashid GeranmayehVaneghi ${ }^{2}$, Vamegh Rasouli ${ }^{3}$, Raoof Gholami ${ }^{1}$ \\ ${ }^{1}$ Faculty of mining, petroleum and geophysics, Shahrood University of Technology, Shahrood, Iran \\ ${ }^{2}$ Rock Mechanics Division, Tarbiat Modares University, Tehran, Iran \\ ${ }^{3}$ Department of Petroleum Engineering, Curtin University, Perth, Australia \\ ${ }^{*}$ E-mail: osaeidi914@gmail.com, Phone: +989149804239
}

\begin{abstract}
A modified empirical criterion is proposed to determine the strength of transversely anisotropic rocks. In this regard, mechanical properties of intact anisotropic slate obtained from three different districts of Iran were taken into consideration. Afterward, triaxial rock strength criterion introduced by Rafiai was modified for transversely anisotropic rocks. The criterion was modified by adding a new parameter $\alpha$ for taking the influence of strength anisotropy into consideration. The results obtained have shown that the parameter $\alpha$ can be considered as the strength reduction parameter due to rock anisotropy. The modified criterion was compared to the modified Hoek-Brown and Ramamurthy criteria for different anisotropic rocks. It was concluded that the criterion proposed in this paper is a more accurate and precise criterion in predicting the strength of anisotropic rocks.
\end{abstract}

Keywords: Transversely anisotropic rock, Strength anisotropy parameter, Triaxial strength criterion, Metamorphic rock.

\section{Introduction}

An anisotropic rock has different properties in different directions. These properties may be of any type: for example, deformability modulus, strength, brittleness, permeability and discontinuity frequency (Hudson and Harrison 2000). Separation of fundamental minerals, in response to high pressure and temperature gradients, is associated with tectonic evolution and development of layers of contrasting mineralogical assemblages.

Many researchers as Colak and Unlu, 2004; Donath, 1964; Horino and Ellickson, 1970; McLamore and Gray, 1967; Kwasniewski, 1993; Ramamurthy, 1993; Karakul, et al., (2010) indicate that most of sedimentary and metamorphic rocks, such as shale and slate, display a strong anisotropy of strength. All the results obtained have shown that the rock strength varies with the loading orientation. The maximum strengths are generally found when the axial compressive stress is nearly normal or parallel to bedding planes. The minimum strength is obtained when the angle between the major stress and bedding planes is located from $30^{\circ}-60^{\circ}$. Furthermore, the failure mode in anisotropic rocks depends also on the loading orientation. Lo et al. (1986) stated that anisotropic behavior of rocks referring to properties such as elasticity, electrical conductivity and permeability is related to the both matrix and pore space distributions.

Although many attempts have been made in the past to describe the strength anisotropy of transversely isotropic rocks, no general methodology has emerged yet. The first attempt seems to be Jaeger's single weakness plane theory (Jaeger, 1960), where two independent failure modes, i.e., failure along the discontinuity and failure through intact material, were assumed to exist. The schematic of loading direction in relation to weakness plane is shown in Fig. 1a. Here, the inclination angle $\beta$ is the angle between the direction of major principal stress and the 
plane of weakness. For those rocks displaying a discrete fabric (i.e., multiple weakness planes), the experimental results have shown that the strength varies continuously with $\beta$ (Fig. 1b).
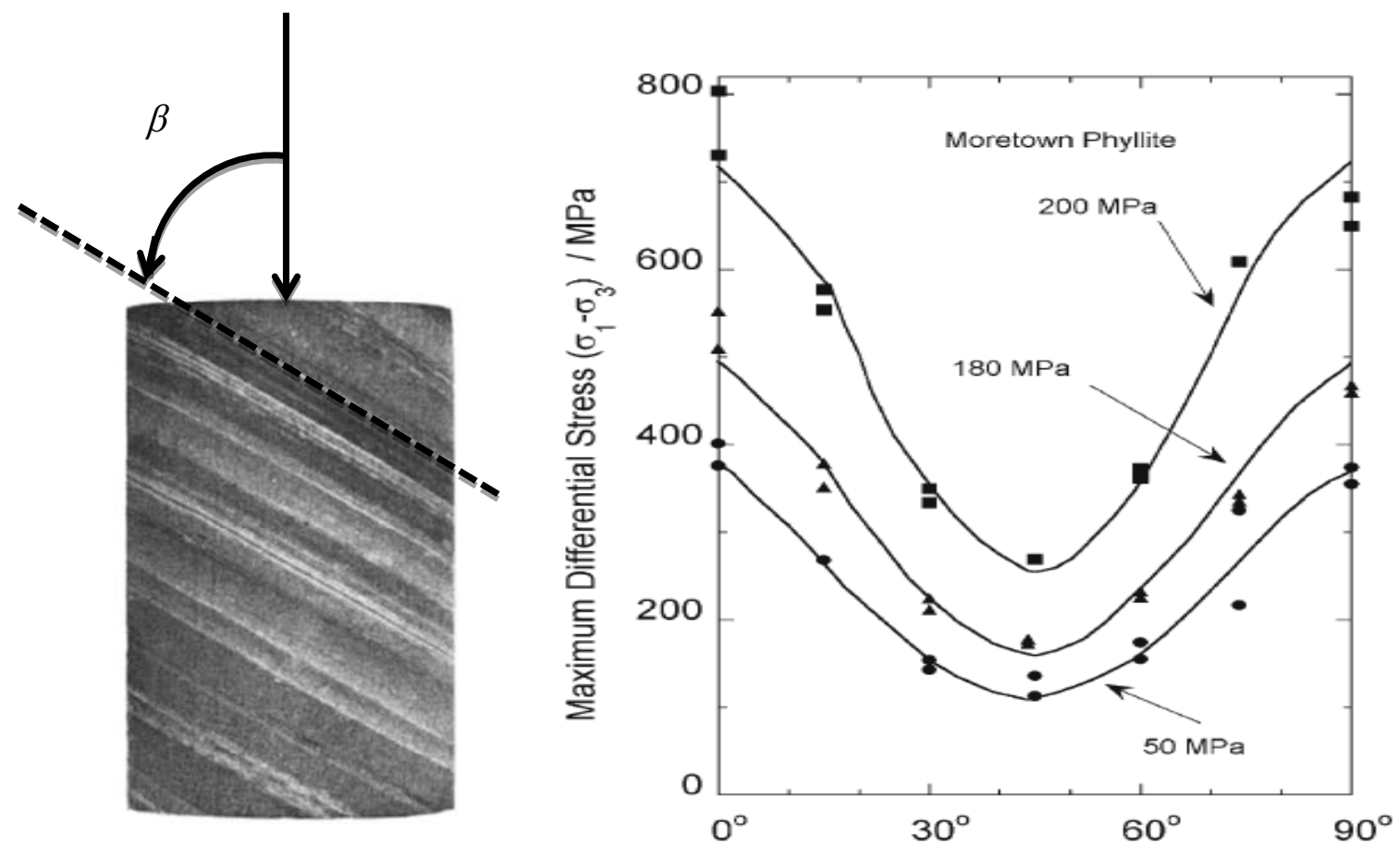

Fig. 1 (a) Angle of weakness plane measured from major loading direction, (b) Variation of differential stress at failure condition of triaxial compression test with respect to plane of weakness (Paterson and Wong, 2005)

In order to reproduce the gradual variation of the strength, Jaeger (Jaeger, 1960) postulated that the cohesion of rock material, within the plane inclined with respect to the weakness plane, was not constant but variable depending on the angle of inclination, whereas the friction angle was considered as constant. More recently, Hoek and Brown (Hoek and Brown, 1980) assumed that the strength parameters $m$ and $s$ in their well-known failure criterion are not constant but variables depending on the direction of weakness plane. However, although the values of $m$ and $s$ are selected based on the orientation of weakness planes, it should be noted that the formulation remain isotropic, so that it is doubtful whether the orientation of failure plane predicted by this approach is realistic. Another drawback of this approach, as well as the earlier one by Jaeger (Jaeger, 1960), is the requirement that the dip direction of weakness planes should coincide with the direction of minor principal stress. In general, however, Jaeger (Jaeger, 1960) and Hoek and Brown's works (Hoek and Brown, 1980) are of importance in that they showed that the failure criterion can be modified to take into account the anisotropy in strength properties. While the applicability of Hoek and Brown $(\mathrm{H}-\mathrm{B})$ approach is restricted, Nova (1980) extended the discussion on anisotropy to the true triaxial stress conditions. Amadei and Savage (Amadei and Savage, 1989) also analyzed the anisotropic strength of jointed rock having a single set of joints in three-dimensional (3D) conditions. In that work, the intact rock strength is described by the $\mathrm{H}-\mathrm{B}$ criterion, whereas the joint strength is modeled by the Coulomb criterion with zero cohesion. Although the variation of material properties with orientation was not directly considered, the authors showed that the strength of the jointed rock 
depends on the direction of weakness planes and the intermediate principal stress. Al-Ajmi and Zimmerman (2006) presented a 3D failure criterion called the Mogi-Coulomb criterion. This failure criterion is a linear failure envelope in the Mogi field. It was shown that the two parameters that play in to be directly and simply related to the two Coulomb strength parameters, the cohesion and the friction angle.

A large number of research papers were documented on strength anisotropy of rocks. Hoek (1964) modified Griffith's theory of brittle fracture for anisotropic slate, Al-Harthi (1998) concentrated on the behavior of sandstones and Attewell and Sandford (1974) worked on shale and slate. Barla and Innaurato (1973) and Barla and Goffi (1974) investigated indirect tensile strength of the anisotropic rocks both experimentally and theoretically. They have determined that depending upon the type of failure, which is observed in testing, either the disc or the ring tests are used to provide the experimental values needed to define the tensile strength. Nasseri et al., (1996 and 1997) investigated the anisotropy on gneiss and schist, Chen and Hsu (2001) worked on strength anisotropy of marble, Saroglou et al., (2004) investigated anisotropic nature of metamorphic rocks from Greece. Ramamurthy et al. (1988 and 1993) assessed the anisotropy of phyllites. Pomeroy et al. (1971) evaluated the strength anisotropy of coal. Allirote and Boehler (1970) focused on strength anisotropy of diatomite while Elmo and Stead (2010) assessed limestone rock pillar anisotropy and Wardle and Gerrard (1972) studied on the strength anisotropy of layered rock and soil masses. In the entire works recently done, it is clearly stated that minimum strength of anisotropic rocks is at the critical weak plane of $45 \pm \varphi / 2$, where $\varphi$ is the friction angle of weak plane. It was also concluded that variation of elastic rock parameters like Young's modulus, Poisson's ratio and tensile strength is similar to that of the ultimate strength.

Nowadays, most of the rock engineering designs and structures are related to the transversely anisotropic rocks with their particular properties. Stability analysis of these structures requires a representative failure criterion. Rafiai (2011) proposed a new empirical failure criterion for intact rock and rock masses under general condition of triaxial and polyaxial stresses. He showed that the criterion could predict the strength of rock over wide range of stresses with high accuracy.

For that reason, in the present study an attempt is made to modify the proposed failure criterion (Rafiai, 2011) to be applicable in representing anisotropic rock strength in triaxial condition. For the aim of this study, mechanical properties of slate from three case studies ( $\mathrm{S}$, G and Z) along with data documented by Saroglou and Tsiambaos (2008) are evaluated to make a comprehensive uniaxial and triaxial database for proposing a modified empirical criterion for anisotropic rocks. The results were compared with those given by the modified Hoek-Brown and Ramamurthy criteria for strength determination of anisotropic rocks.

\section{Geological description and rock strength database}

To evaluate the behavior of anisotropic rocks under triaxial test condition, a database containing testing results of four common anisotropic rocks was collected. slate $\mathrm{S}$ and $\mathrm{G}$ were obtained from Sardasht dam right bank and Golpayegan road tunnel, respectively. In addition, Seyedi (2005) conducted a complete triaxial and uniaxial test series on the slate $\mathrm{Z}$ obtained from Zhave dam of Iran. Geological description of these three areas is as in follow: 
Sardasht dam site: Dominant lithology in the area is grey slate rock formed as result of a very low-grade metamorphism of mudstone (Darvishzadeh, 1991). However, detailed studies revealed some interbeds and intercalations of sandstone, metamorphic siltstone and silts regionally altered to slate that formerly contained varied quantity of silt and sand. Furthermore, milky quartzite can be seen in different forms scattered in the rock and in the form of layers and podiforms. Originated from mudstone, sandstone and siltstone these geological setting then caused by directional pressures and regional metamorphism (Taleghani, 2002). Geologists classified the slate in this area from completely weathered to slightly weathered rock due to erratic weather conditions.

Golpayegan road tunnel: The tunnel is driven in Sannadaj-Sirjan geological zone of central Iran. Schistosity and recrystallization of minerals is the common phenomena due to incidence series of asymmetric foldings and faults and mild to high metamorphisms in the region. Lithology of the area consists of a sequence of Jurassic-cretaceous formations. The cretaceous formations comprise massive limestone and dolomite, while the Jurassic formation mainly consists of slate, schist and in some parts metamorphic shale and sandstone (Darvishzadeh, 1991).

Zhaveh dam site: Dominant lithology in the area is slate where microcrystalline limestone, mudstone and silt bearing limestones and sandy limestone were observed in some parts in the region. Existence of rhombic pyrite minerals in the bedrock shows the upper cretaceous origin of the medium. Metamorphic rocks formed with simultaneous effects of intrusion and alpine tectonic motions. Most of the rocks foliated because of the metamorphic effects where in deep area degree of foliation decreases due to less weathering and high pressures (Darvishzadeh, 1991).

Figure 2 (a) and (b) shows those places where rock blocks were obtained as well as in Fig. 2 (c) plan of the right bank of the Sardasht dam where stars show sampling locations for slate and dash lines shows the location of rock slopes. Figure 2 (d) shows samples of slate $\mathrm{Z}$ prepared for triaxial testing. 
(c)
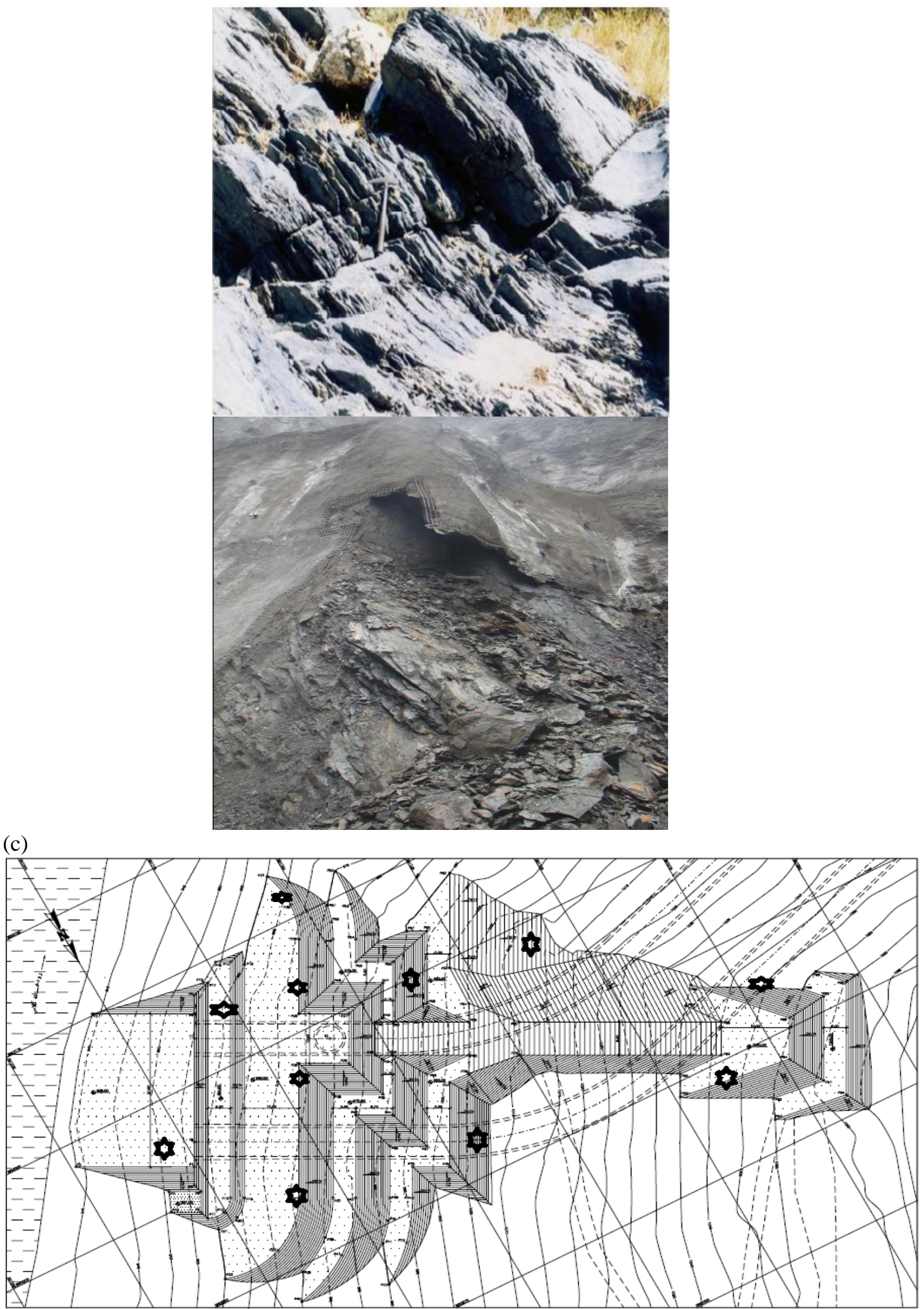
(d)

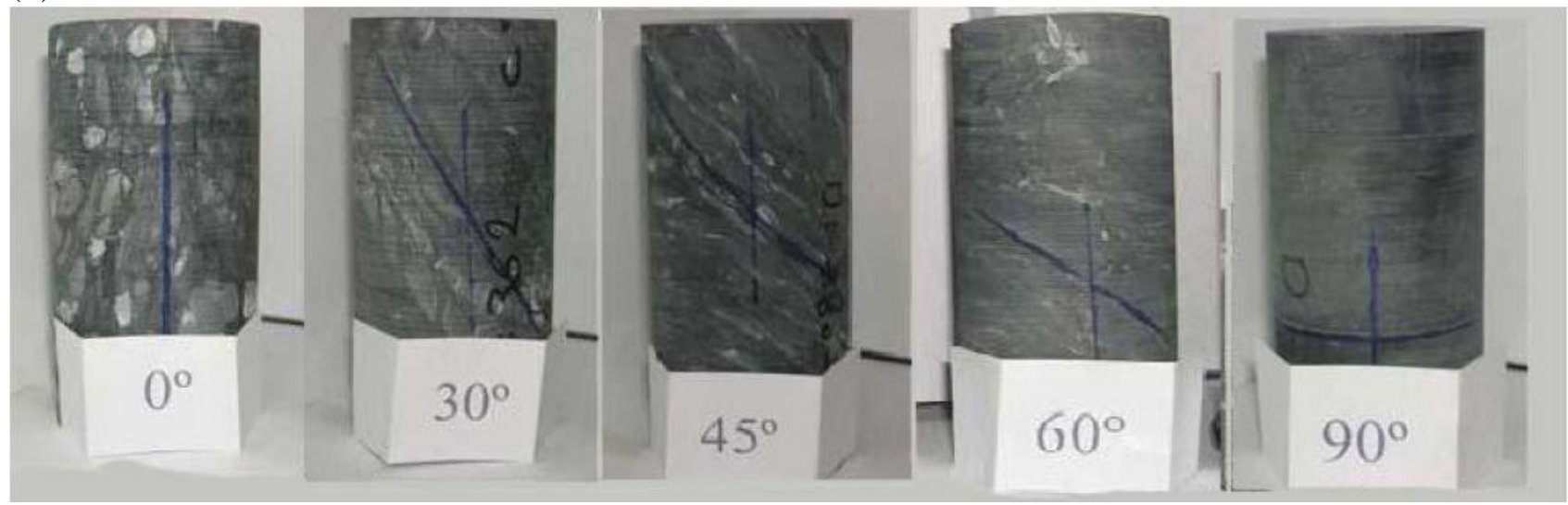

Fig. 2 (a) Outcrop view of the slate at Golpayegan water tunnel used for obtaining slate G; (b) Blocks of a collapsed berm in Sardasht dam used for obtaining slate S; (c) Plan view of the right bank of Sardasht dam where stars shows the sampling location for slate and dash lines shows the stabilizing berms; (d) Samples prepared from Zhaveh Dam site (slate Z)

Furthermore, the triaxial and uniaxial tests of gneisses A and B, schist and marble documented by Saroglou and Tsiambaos (2008) were taken into account to validate the findings. Table 1 shows the available data and ranges of $\sigma_{c}, \sigma_{1}$ and $\sigma_{3}$ with respect to the anisotropy orientation $\beta$ for each rock type used in the present study. Petrological description of Gneiss A-B, Schist and Marble was presented in Saroglou and Tsiambaos (2008).

Table 1 Uniaxial and Triaxial data set of different anisotropic rocks used for present study 


\begin{tabular}{|c|c|c|c|c|c|c|c|c|c|c|c|c|c|c|c|c|}
\hline \multirow[b]{3}{*}{ Rock type } & \multirow[b]{3}{*}{$\begin{array}{c}\text { No. of pair } \\
\text { data }\end{array}$} & \multicolumn{5}{|c|}{$\beta=0$} & \multicolumn{5}{|c|}{$\beta=15$} & \multicolumn{5}{|c|}{$\beta=30$} \\
\hline & & \multicolumn{2}{|c|}{$\sigma_{3}$} & \multicolumn{2}{|c|}{$\sigma_{1}$} & \multirow[b]{2}{*}{$\sigma_{c}$} & \multicolumn{2}{|c|}{$\sigma_{3}$} & \multicolumn{2}{|c|}{$\sigma_{1}$} & \multirow[b]{2}{*}{$\sigma_{c}$} & \multicolumn{2}{|c|}{$\sigma_{3}$} & \multicolumn{2}{|c|}{$\sigma_{1}$} & \multirow[b]{2}{*}{$\sigma_{c}$} \\
\hline & & $\begin{array}{c}\mathrm{Mi} \\
\mathrm{n}\end{array}$ & Max & Min & Max & & $\begin{array}{c}\mathrm{Mi} \\
\mathrm{n}\end{array}$ & Max & Min & $\begin{array}{c}\mathrm{Ma} \\
\mathrm{x}\end{array}$ & & $\begin{array}{c}\mathrm{Mi} \\
\mathrm{n}\end{array}$ & Max & $\begin{array}{c}\mathrm{Mi} \\
\mathrm{n}\end{array}$ & Max & \\
\hline Slate $S$ & 47 & 0 & 30 & 33 & 220 & 50 & 0 & 15 & 25 & 70 & 20 & 0 & 18 & 15 & 90 & 8 \\
\hline Slate G & 15 & 5 & 20 & 105 & 210 & 92 & - & - & - & - & - & 5 & 20 & 33 & 59 & 25 \\
\hline Slate Z & 15 & 3 & 10 & 53 & 91 & 32 & - & - & - & - & - & 3 & 10 & 26 & 40 & 10 \\
\hline Gneiss A* & 34 & 0 & 31 & 43 & 270 & 42 & - & - & - & - & - & 0 & 12 & 21 & 81 & 22 \\
\hline Gneiss B ${ }^{*}$ & 36 & 0 & 31 & 33 & 201 & 39 & - & - & - & - & - & 0 & 29 & 22 & 132 & 18 \\
\hline Schist ${ }^{*}$ & 39 & 0 & 31 & 58 & 228 & - & 0 & 31 & 58 & 160 & & 0 & 31 & 52 & 179 & - \\
\hline Marble $^{*}$ & 38 & 0 & 40 & 80 & 242 & 80 & - & - & - & - & - & 0 & 46 & 71 & 230 & 78 \\
\hline
\end{tabular}

\begin{tabular}{cccccccccccccccccc}
\hline \multicolumn{1}{c}{$\beta=45$} & \multicolumn{1}{c}{$\beta=60$} & \multicolumn{1}{c}{$\beta=90$} \\
\hline \multicolumn{1}{c}{$\sigma_{3}$} & \multicolumn{1}{c}{$\sigma_{1}$} & \multicolumn{1}{c}{$\sigma_{3}$} & \multicolumn{1}{c}{$\sigma_{1}$} & & $\sigma_{3}$ & \multicolumn{1}{c}{$\sigma_{1}$} \\
\hline Min & Max & Min & Max & $\sigma_{c}$ & Min & Max & Min & $\begin{array}{c}\text { Ma } \\
\text { x }\end{array}$ & $\sigma_{c}$ & Min & Max & Min & $\begin{array}{c}\text { Ma } \\
\text { x }\end{array}$ & $\sigma_{c}$ \\
\hline- & - & - & - & - & 0 & 18 & 0 & 100 & 40 & 0 & 35 & 55 & 250 & 65 \\
5 & 20 & 39 & 64 & 28 & 5 & 20 & 50 & 80 & 35 & 5 & 20 & 141 & 287 & 126 \\
3 & 10 & 30 & 61 & 21 & 3 & 10 & 42 & 80 & 33 & 3 & 10 & 124 & 189 & 96 \\
0 & 31 & 38 & 156 & 41 & - & - & - & - & - & 0 & 31 & 58 & 257 & 61 \\
0 & 31 & 38 & 133 & 25 & - & - & - & - & - & 0 & 46 & 85 & 360 & 85 \\
0 & 31 & 52 & 179 & - & 3.6 & 31 & 88 & 188 & - & 0 & 46 & 67 & 236 & 67 \\
0 & 46 & 85 & 244 & 75 & 0 & 19 & 69 & 170 & 100 & 0 & 46 & 80 & 253 & 90 \\
\hline
\end{tabular}

\section{Sample preparation and testing}

Representative cubic rock samples in $20 \times 30 \times 20 \mathrm{~cm}$ dimensions for slate $\mathrm{S}, \mathrm{G}$ and $\mathrm{Z}$ were prepared and transported to the laboratory. The samples cored at different direction respect to the plane of anisotropy $(\beta)$ of $0^{\circ}, 15^{\circ}, 30^{\circ}, 45^{\circ}, 60^{\circ}$ and $90^{\circ}$. Each sample was prepared according to ISRM suggested method (ISRM, 2007) with diameter of $54 \mathrm{~mm}$ and length to diameter ratio of 2-3. Ends of each sample were ground to be flat to $\pm 0.01 \mathrm{~mm}$ and parallel to each other. The deviation in the diameter and undulation of the ends were less than $0.2 \mathrm{~mm}$. The vertical deviation was less than 0.001 radian. Triaxial tests were carried out using multistage loading method (ISRM, 2007) and most of the samples failed in 5 to 15 minutes. In this method confining pressure is increased stage by stage manually as the axial pressure increases where at all times axial loads exceed confining pressure by no more than on tenth of the rock UCS until peak stress reached. Therefore, in this study, slate $S, G$ and $Z$ were tested with confining pressure ranges 3-35MPa (Table 1). Because of the difficulty of sample gathering and preparing in the regions for slate $\mathrm{G}$ and $\mathrm{Z}$ then minimum numbers of samples were obtained. However, according to ISRM (2007) five to ten samples is sufficient for triaxial tests. 
Thin sections of the samples were prepared perpendicular to the foliations (Fig. 3), petrography analysis revealed that slate $S$ is mainly consisted of quartzite and meta-sandstone veins with very thin interbeddings of clay, shale, some organic detritus and volcanic ash while slate $G$ contains mica and muscovite, and slate $\mathrm{Z}$ includes crystals of quartz and feldspar. Quartzitic slate $S$ and $Z$ were mainly made up of cryptocrystalline to fine grained flaky micaceous minerals, preferably oriented with fine-grained recrystallized quartz, which are in abundance. In addition, analyses showed that the preferred orientation (texture) of the quartzite was almost parallel to the apparent direction of slate foliation.

(a)

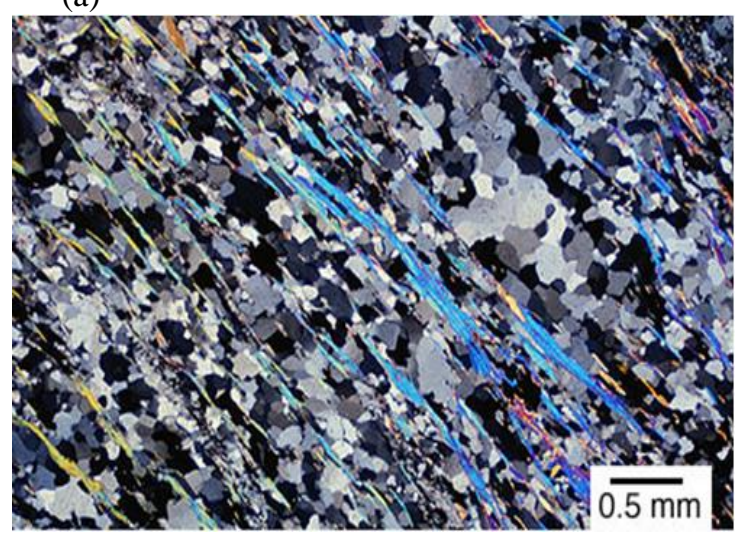

(b)

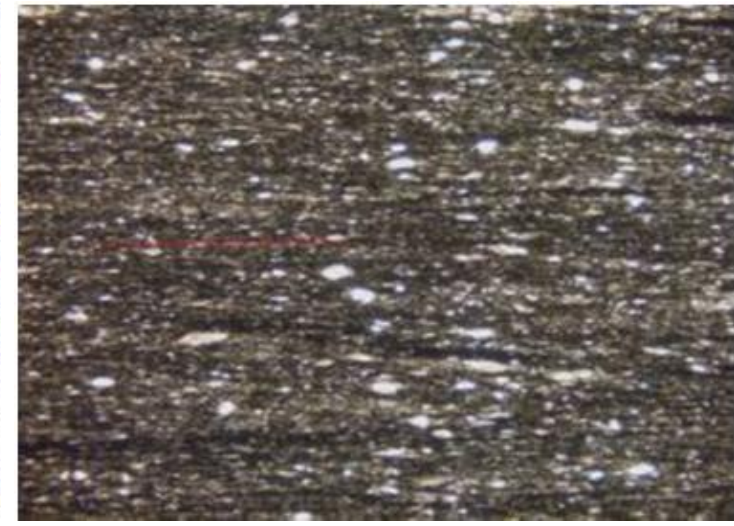

(c)

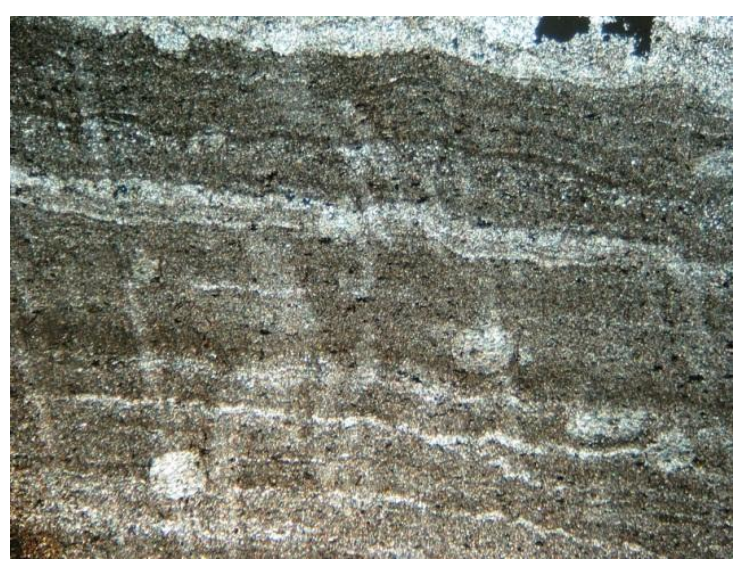

Fig. 3 Thin sections of studied rock samples obtained perpendicular to the foliation, (a) slate G, (b) slate Z, (c) slate $\mathrm{S}$

\section{Anisotropic behavior of the slate in uniaxial compressive strength condition}

The most commonly used equation relating rock strength and direction of anisotropy was initially introduced by Jaeger (1960) and modified by Donath (1961). This equation is as follow:

$\sigma_{c \beta}=A-D \cos 2\left(\beta-\beta_{\text {min }}\right)$

Where $\sigma_{c \beta}$ is the uniaxial compressive strength at angle $\beta$ of weakness planes, $\beta$ is the weakness plane orientation regarding the maximum loading, $\beta_{\min }$ is the angle of minimum uniaxial compressive strength, $A$ and $D$ are constant parameters. To determine the values of parameters $A$ and $D$, uniaxial compressive strength data at the angles of weakness plane, $0^{\circ}$, $30^{\circ}$ and $90^{\circ}$ is required. Hence, available uniaxial strength data (i.e. those data presented in Table 1) and Eq. (1) were used to determine the constants parameters $A$ and $D$. Since 
Parameter $D$ is related to the strength anisotropy, value of this parameter represents the strength anisotropy effect. Generally, the strength variation of intact rock in uniaxial and triaxial loading conditions with respect to the anisotropy orientation is defined as the strength anisotropy and its magnitude is representing the degree of anisotropy (Eq. (2)).

$$
R_{c}=\frac{\sigma_{c i(90)}}{\sigma_{c i(\min )}}
$$

Where $R_{c}$ is the degree of anisotropy, $\sigma_{c i(90)}$ is the uniaxial compressive strength perpendicular to the planes of anisotropy and $\sigma_{c i(\min )}$ is the minimum value of $\sigma_{c i}$. In addition, strength anisotropy can be represented in terms of Young's modulus as $E_{\max } / E_{\min }$, where $E_{\max }$ and $E_{\min }$ , respectively, are the maximum and minimum values of Young's modulus in the anisotropic rocks (Amadei, 1966). Table 2 compares the degree of strength anisotropy in slate $S, G$ and $Z$ according to the definitions mentioned. The data for gneiss A-B, schist and marble was provided from Saroglou and Tsiambaos (2008). Indeed no information have been given on Young's modulus in their paper as well as $D$ and $A$ for schist.

Table 2 Strength anisotropy parameters in uniaxial compression test for different rock types

\begin{tabular}{cccccccc}
\hline Parameter & Slate S & Slate G & Slate Z & Gneiss A & Gneiss B & Schist $^{*}$ & Marble $^{*}$ \\
\hline$R_{c}$ & 4.33 & 5.04 & 3.06 & 2.2 & 3.8 & 1.25 & 1.14 \\
$\frac{E_{\max }}{E_{\min }}$ & 4.2 & 4.72 & 3.4 & - & - & - & - \\
D & 37.68 & 68.86 & 56.7 & 26.1 & 43.8 & - & 11.2 \\
A & 52.93 & 93.78 & 65.6 & 52.7 & 61.5 & - & 83.9 \\
\hline
\end{tabular}

According to the obtained ratios $(\geq 3)$ presented in Table 2, slate $\mathrm{S}, \mathrm{G}$ and $\mathrm{Z}$ are categorized as the highly anisotropy rocks (Colak and Unlu, 2004; Ramamurthy, 1993). Figure 4 (a) to (d) shows the variation of uniaxial compressive strength and Young's modulus of the slate $\mathrm{S}, \mathrm{Z}$, and $\mathrm{G}$ with respect to anisotropy orientation $\beta$, respectively. It should be noted that the maximum strengths are obtained when the applied load is perpendicular to the foliation. However, minimum strengths of the slate are determined when the angle of foliation and applied load make an approximate degree of $30^{\circ}$. Singh et al., (2002) and Nasseri et al., (2003) also showed the variation of Young's modulus with the angle of anisotropy in a U-shaped trend. However, in some rock types as graywake schist, shale and coal the variations tended to decrease in order-shaped trends (See Nasseri et al. 2003). In this case (Fig. 4b-d), Young's modulus decreases when the angle of weakness plane reaches $30^{\circ}$ and then increases in the nearly U-Shaped trend. 
Table 3 Cohesive strength and friction of the slate G, S and Z

\begin{tabular}{ccccc}
\hline & \multicolumn{2}{c}{$\beta=0^{\circ}$} & \multicolumn{2}{c}{$\beta=90^{\circ}$} \\
\hline & $\mathrm{C}(\mathrm{MPa})$ & $\varphi$ & $\mathrm{C}(\mathrm{MPa})$ & $\varphi$ \\
\hline Slate $\mathrm{G}$ & 15.45 & 47.7 & 17.52 & 53.7 \\
Slate $\mathrm{S}$ & 8 & 43.2 & 15.75 & 44.4 \\
Slate Z & 10.12 & 47.4 & 16.67 & 42.9 \\
\hline
\end{tabular}

It can be inferred from Table 3 that cohesive strength and friction may be of the main reasons explaining different behaviors of the studied rock types.

\section{Anisotropic behavior of the slate in triaxial condition}

\section{Modified Hoek-Brown criterion}

Saroglou and Tsiambaos (2008) modified the Hoek-Brown criterion (Hoek and Brown, 1980) by adding a strength anisotropy coefficient $K_{\beta}$, as follow:

$\sigma_{1}=\sigma_{3}+\sigma_{c \beta}\left(K_{\beta} m_{i} \frac{\sigma_{3}}{\sigma_{c \beta}}+1\right)^{0.5}$

Where $\sigma_{c \beta}$ is the uniaxial compressive strength at the anisotropy orientation $\beta$ and $K_{\beta}$ is the parameter of strength anisotropy. The intact rock parameter $m_{i}$ varies from 4 for very fine weak rock like claystone to 33 for coarse igneous light-colored rock like granite (Hoek, 1990). Saroglou and Tsiambaos (2008) also mentioned that the ratio of $K_{90} / K_{30}$ can be considered as the strength anisotropy effect. It was concluded that the parameter $m_{i}$ is the characteristic of each rock and independent from loading orientation. Figure 5 shows the variation of $K_{\beta}$ with the anisotropy orientation for slate $\mathrm{S}, \mathrm{G}$ and $\mathrm{Z}$. 


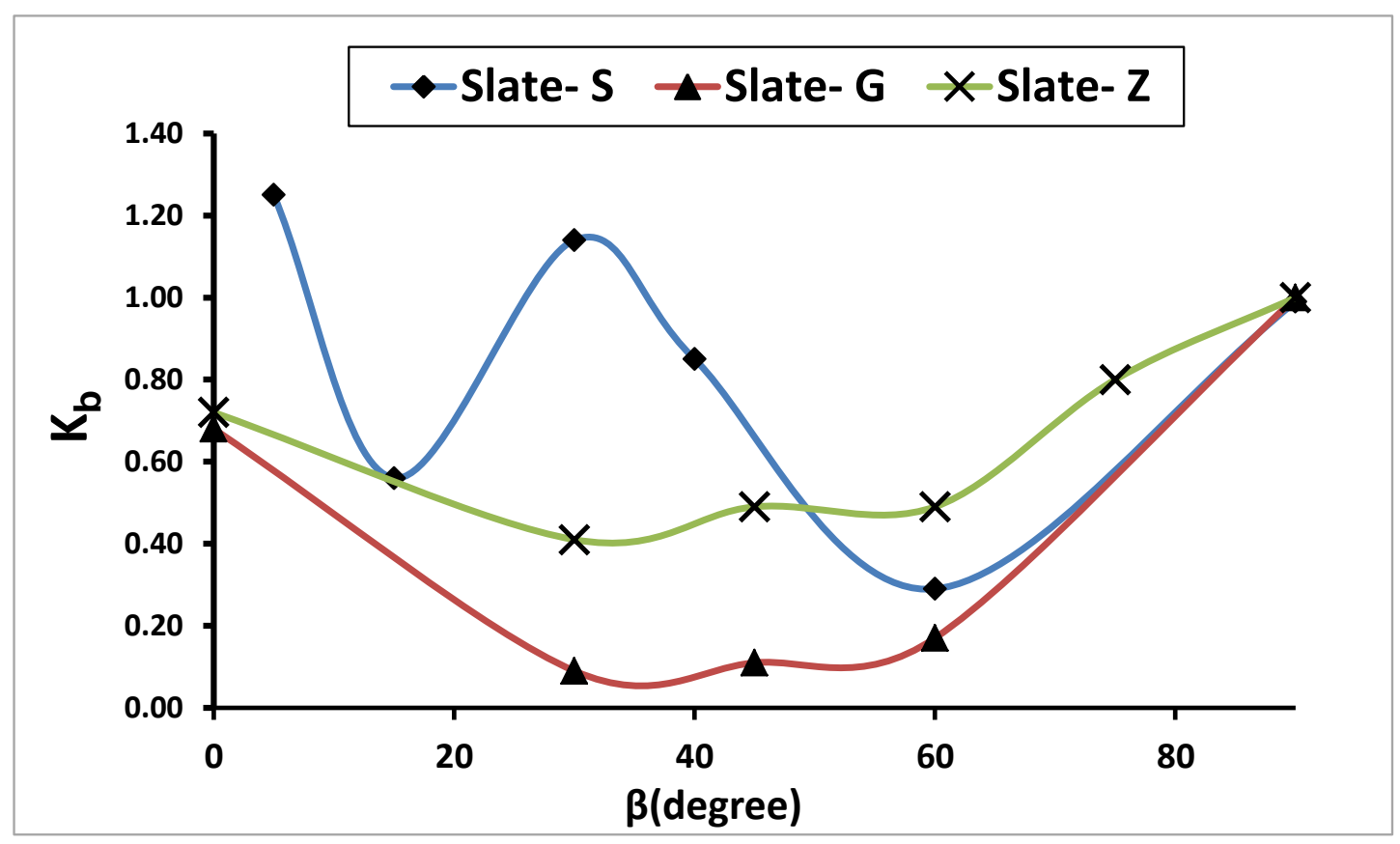

Fig. 5 Variation of $K_{\beta}$ parameter with anisotropy orientation of slate for slate $\mathrm{S}, \mathrm{G}$ and Z

Figure 5 shows the statement of Saroglou and Tsiambaos (2008) implying the strong relationship of $K_{\beta}$ with anisotropy orientation of slate. However, the variation of $K_{\beta}$ for slate $\mathrm{S}$ is different from others and has erratic pattern with angle $\beta$ similar to its modulus variation in Fig. 4b. It may relate to the petrological properties of the slate $S$ as mentioned previously where presence of thin interbeddings of clay, shale, some organic detritus and volcanic ash may affect its mechanical properties. Results of the present work indicate that the parameter $m_{i}$ cannot relate to anisotropy orientation as Colak and Unlu (2004) declared in their work. The values of $m_{i}$ in the current study were obtained as 13.4, 12.1, 11.5, 24.6, 23.2, 9.5 and 9.6 for slate $\mathrm{S}, \mathrm{G}$ and $\mathrm{Z}$, gneiss $\mathrm{A}$ and $\mathrm{B}$, schist and marble, respectively. However, the modified criterion of the Hoek-Brown is limited to the triaxial condition and cannot predict the effect of intermediate principal stress $\left(\sigma_{2}\right)$ on anisotropic rock strength because the basic failure criterion of Hoek-Brown (Hoek and Brown, 1980) is incapable of prediction rock strength in true-triaxial condition.

\section{Ramamurthy criterion}

Ramamurthy et al. (1988) and Rao et al. (1986) proposed an empirical strength criterion to predict non-linear strength behavior of intact anisotropic rocks as follow:

$$
\frac{\left(\sigma_{1}-\sigma_{3}\right)}{\sigma_{3}}=B_{j}\left(\frac{\sigma_{c j}}{\sigma_{3}}\right)^{\alpha_{j}}
$$

Where $\sigma_{1}$ and $\sigma_{3}$ are the major and minor principal stresses, and $\sigma_{c j}$ is the uniaxial compressive strength at the particular anisotropy orientation $\beta$. Material strength anisotropy is taken into account here by defining the parameters $\alpha_{j}$ and $B_{j}$ as the functions of anisotropy orientation as: 


$$
\begin{aligned}
& \frac{\alpha_{j}}{\alpha_{90}}=\left(\frac{\sigma_{c j}}{\sigma_{c 90}}\right)^{1-\alpha_{90}} \\
& \frac{B_{j}}{B_{90}}=\left(\frac{\alpha_{90}}{\alpha_{j}}\right)^{0.5}
\end{aligned}
$$

Where $\sigma_{c 90}$ is the uniaxial compressive strength in $\beta=90$, and $\alpha_{90}$ and $B_{90}$ are regarded as the values of $\alpha_{j}$ and $B_{j}$ in $\beta=90$. In the current study, a few triaxial data at $\beta=90$ has resulted in obtaining parameters $\alpha_{90}$ and $B_{90}$ from log-log plot of $\left(\sigma_{1}-\sigma_{3}\right) / \sigma_{3}$ and $\sigma_{c 90} / \sigma_{3}$. Substituting the obtained parameters into Eq. (5), $\alpha_{j}$ and $B_{j}$ can be calculated at any weakness planes. The modified criterion of the Ramamurthy criterion validated in triaxial condition, however, it cannot predict the effect of intermediate principal stress $\left(\sigma_{2}\right)$ on anisotropic rock strength. Furthermore, the criterion has not been validated for prediction of rock mass strength.

\section{A modified rock failure criterion for anisotropic rocks}

\section{Introduction}

Rafiai (2011) proposed a new rock failure criterion for isotropic rocks, which can be fitted to the polyaxial and triaxial test data. The proposed empirical criterion is used for prediction of intact rock brittleness and ductility, and can also be extended to rock mass strength. This empirical failure criterion in triaxial loading condition expressed as:

$$
\frac{\sigma_{1}}{\sigma_{c i}}=\frac{\sigma_{3}}{\sigma_{c i}}+\left[\frac{1+A\left(\sigma_{3} / \sigma_{c i}\right)}{1+B\left(\sigma_{3} / \sigma_{c i}\right)}\right]-r
$$

Where $\sigma_{c i}$ is the uniaxial compressive strength of intact rock and $A$ and $B$ are constant parameters, depending on the properties of rock. The parameter $r$ is the strength reduction factor indicating the extent to which the rock mass has been fractured. This parameter is considered equal to zero for intact rock and equal to one for heavily jointed rock masses.

To apply the failure criterion (Eq. 6) for transversely anisotropic rocks fitting procedure was conducted on the gathered database using Matlab software. As mentioned, the parameter $r$ is considered equal to zero due to intact state of the rock. The results have shown that a new parameter as the strength reduction parameter should be taken into consideration for extending the generalization of Eq. (6) for anisotropic rocks. The modified criterion can be expressed as follow:

$$
\sigma_{1}=\sigma_{3}+\sigma_{c \beta}\left[\frac{1+A\left(\sigma_{3} / \sigma_{c \beta}\right)}{\alpha+B\left(\sigma_{3} / \sigma_{c \beta}\right)}\right]
$$

Where $\sigma_{c \beta}$ is the uniaxial compressive strength of intact anisotropic rock at anisotropy orientation, $\alpha$ is the strength reduction parameter regarded the rock anisotropy, and $A$ and $B$ are constants parameters.

\section{Modified criterion in triaxial condition}

At this step, attempts have been made to fit the new proposed modified criterion, the modified Hoek-Brown and the Ramamurthy criteria to the anisotropic rocks in triaxial condition. Two methods of fitting were used to fit the relations to the triaxial data. Simple linear regression was used to fit the modified Hoek-Brown and Ramamurthy criteria and non- 
linear regression was considered to fit the new modified criterion (Eq. 7) using Matlab software (Matlab, 2009). Two algorithms of fitting, Levenberg-Marquardt and Trust-Region, were applied and the best correlation coefficient and Root Mean Square Errors (RMSE) were determined. Correlation coefficient and root mean square errors are criteria used for assess the goodness of fit. To obtain constants of the modified triaxial criterion of Eq. (7) it can be rewritten in the form

$Z=A X-B Y$

Where

$X=\frac{\sigma_{3}}{\sigma_{c \beta}}$

$Y=\frac{\sigma_{3}}{\sigma_{c \beta}}\left(\frac{\sigma_{1}}{\sigma_{c \beta}}-\frac{\sigma_{3}}{\sigma_{c \beta}}\right)$

$Z=\alpha\left(\frac{\sigma_{1}}{\sigma_{c \beta}}-\frac{\sigma_{3}}{\sigma_{c \beta}}\right)-1$

The values of $A$ and $B$ can be calculated as

$$
\begin{aligned}
A & =\frac{\sum X Y \sum Y Z-\sum Y^{2} \sum X Z}{\left(\sum X Y\right)^{2}-\sum X^{2} \sum Y^{2}} \\
B & =\frac{\sum X^{2} \sum Y Z-\sum X Y \sum X Z}{\left(\sum X Y\right)^{2}-\sum X^{2} \sum Y^{2}}
\end{aligned}
$$

The generic acceptability of a rock failure criterion depends greatly on its application in wide range of rock mechanical tests. Figure 6 compares the failure envelops of the new modified criterion and those of the modified Hoek-Brown and Ramamurthy criteria for different rock types at three different anisotropy orientations, $\beta=0^{\circ}, 30^{\circ}, 90^{\circ}$.

(a)

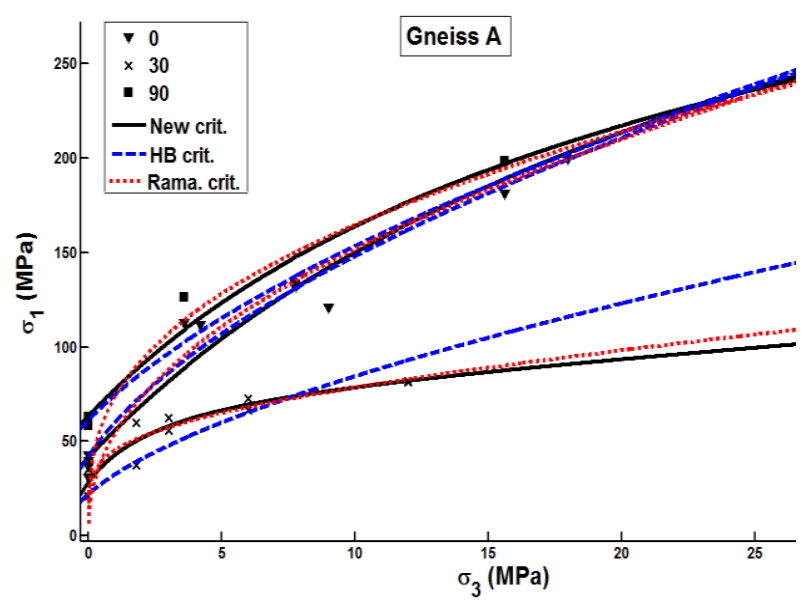

(c) (b)

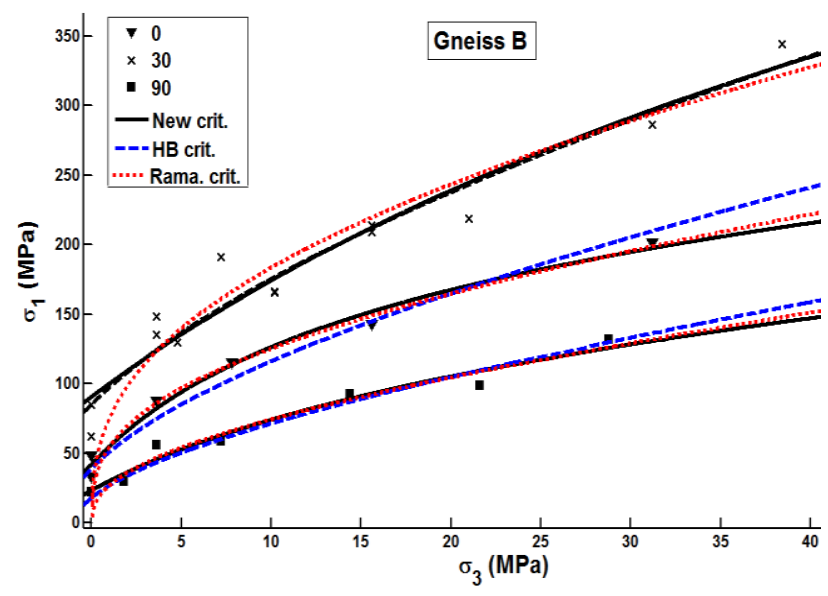



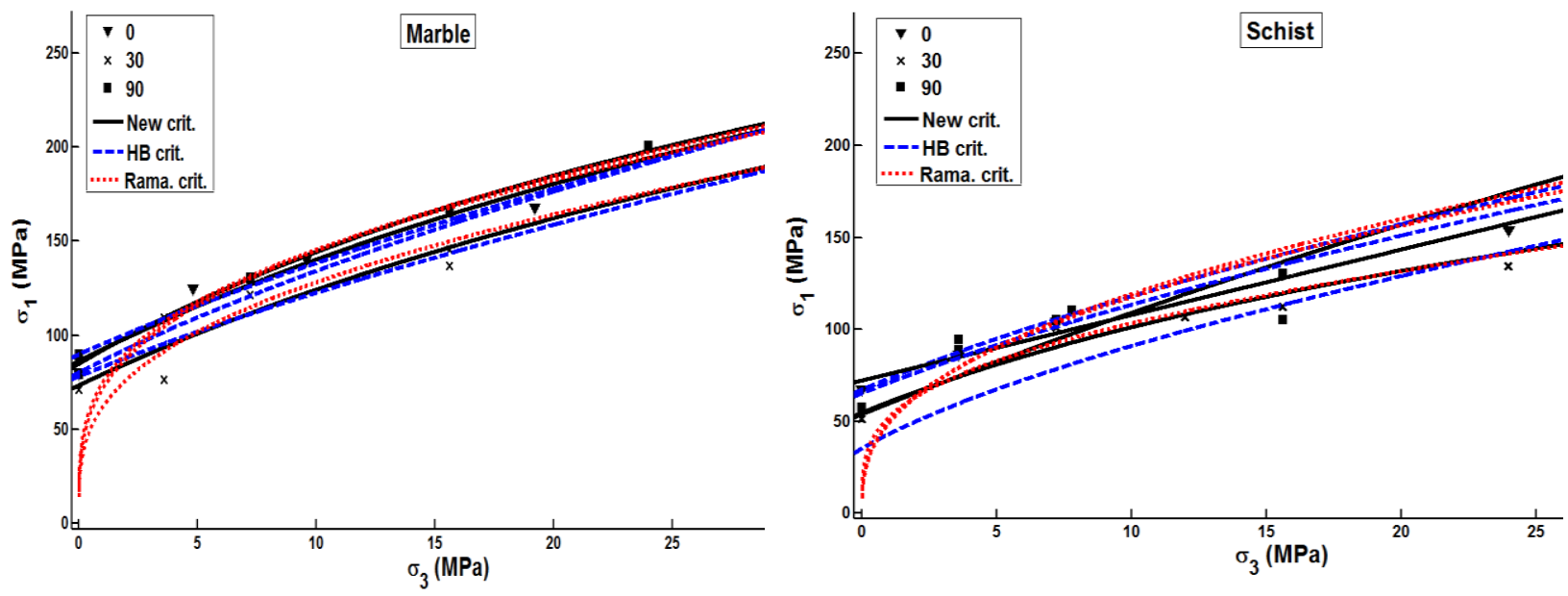

(e)
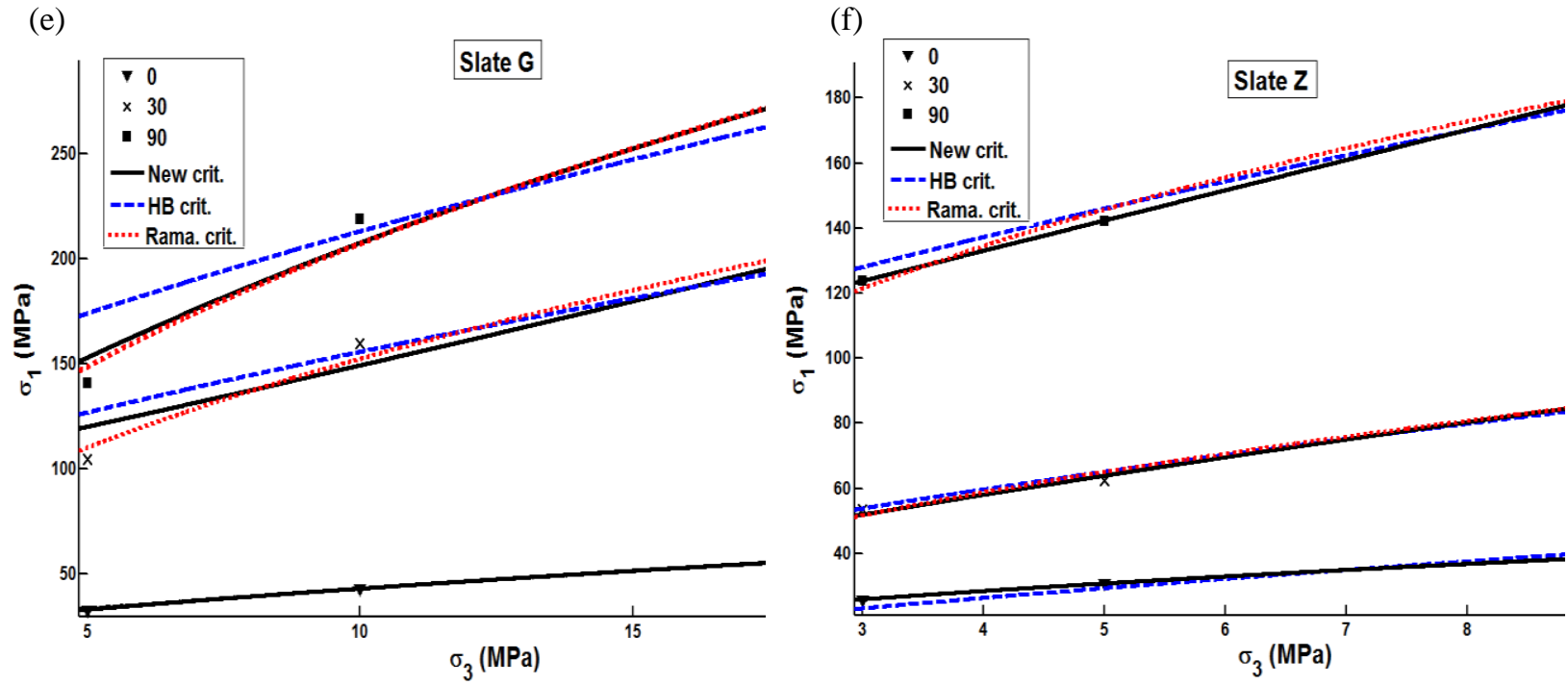

Fig. 6 Comparison of failure envelopes of the new modified, modified Hoek-Brown and Ramamurthy criteria for different anisotropic rocks

It can be seen that the new modified criterion well fitted to the triaxial data for anisotropic rocks than those of the modified Hoek-Brown and Ramamurthy criteria. The curvature of the new criterion envelope is quite approporiate and shows high non-linearity. The results of the analysis on the three criteria using Eq. (9-13) for intact anisotropic rocks are given in Table 4.

Table 4 Obtained parameters from fitting the new modified, the modified Hoek-Brown and the Ramamurthy criteria for different anisotropic rock types

\begin{tabular}{ccccccccccccc}
\hline \multicolumn{11}{c}{ Gneiss A } \\
\hline \multicolumn{110}{c}{ H-B criterion } & \multicolumn{10}{c}{ Ramamurthy criterion } & \multicolumn{1}{c}{ New modified criterion } \\
\hline$\beta$ & $\sigma_{c \beta-l a b}$ & $k_{\beta}$ & $R^{2}$ & $\alpha_{j}$ & $B_{j}$ & $R^{2}$ & $\alpha$ & $A$ & $B$ & $\sigma_{c-p r}$ & $R^{2}$ \\
\hline 0 & 39.4 & 1.79 & 0.98 & 0.57 & 6.2 & 0.87 & 1.11 & 17.5 & 2.15 & 40.6 & 0.97 \\
30 & 35.5 & 0.42 & 0.67 & 0.8 & 3.61 & 0.45 & 0.8 & 22.77 & 6.3 & 21 & 0.90 \\
90 & 66.5 & 1 & 0.97 & 0.67 & 4.58 & 0.73 & 0.98 & 17.08 & 3.31 & 61 & 0.98
\end{tabular}




\begin{tabular}{|c|c|c|c|c|c|c|c|c|c|c|c|}
\hline \multirow[b]{2}{*}{0} & \multirow[b]{2}{*}{45.4} & \multicolumn{10}{|c|}{ Gneiss B } \\
\hline & & 0.88 & 0.97 & 0.67 & 4.61 & 0.77 & 0.93 & 14.16 & 2.47 & 38 & 0.98 \\
\hline 30 & 23.4 & 0.59 & 0.96 & 0.6 & 4.5 & 0.90 & 0.75 & 5.38 & 0.63 & 19 & 0.97 \\
\hline \multirow[t]{2}{*}{90} & 85.7 & 1.01 & 0.96 & 0.63 & 4.44 & 0.83 & 0.95 & 9.55 & 1.37 & 87 & 0.95 \\
\hline & & \multicolumn{10}{|c|}{ Marble } \\
\hline 0 & 88.1 & 0.99 & 0.97 & 0.73 & 2.92 & 0.53 & 0.94 & 6.84 & 1.7 & 81 & 0.98 \\
\hline 30 & 76.1 & 0.91 & 0.96 & 0.71 & 2.73 & 0.73 & 0.85 & 7.15 & 1.92 & 77 & 0.96 \\
\hline \multirow[t]{2}{*}{90} & 89.7 & 1 & 0.98 & 0.71 & 2.8 & 0.35 & 1.02 & 9.64 & 2.95 & 87 & 0.99 \\
\hline & & \multicolumn{10}{|c|}{ Schist } \\
\hline 0 & 66 & 1.32 & 0.88 & 0.64 & 3.21 & 0.71 & 1.2 & 6.83 & 0.8 & 65 & 0.88 \\
\hline 30 & 25 & 0.77 & 0.83 & 0.73 & 3.68 & 0.62 & 0.64 & 4.61 & 0.87 & 27 & 0.91 \\
\hline \multirow[t]{2}{*}{90} & 67 & 1.04 & 0.99 & 0.65 & 3.01 & 0.65 & 0.96 & 2.48 & 0.013 & 66 & 0.99 \\
\hline & & \multicolumn{10}{|c|}{ Slate $\mathbf{G}$} \\
\hline 0 & 92 & 0.68 & 0.9 & 0.56 & 4.08 & 0.98 & 1 & 4.05 & 0.5 & 92 & 0.94 \\
\hline 30 & 25 & 0.087 & 0.99 & 0.76 & 1.64 & 0.96 & 0.75 & 3.93 & 1.77 & 26 & 1 \\
\hline \multirow[t]{2}{*}{90} & 126 & 1 & 0.88 & 0.54 & 5 & 0.95 & 1.5 & 25.56 & 5.42 & 125 & 0.97 \\
\hline & & \multicolumn{10}{|c|}{ Slate $Z$} \\
\hline 0 & 32 & 0.73 & 0.98 & 0.58 & 4.01 & 0.95 & 1 & 6.82 & 0.79 & 31 & 0.99 \\
\hline 30 & 11 & 0.38 & 0.86 & 0.76 & 2.8 & 0.94 & 0.7 & 3.54 & 0.93 & 12 & 1 \\
\hline \multirow[t]{2}{*}{90} & 96 & 1 & 0.97 & 0.66 & 3.96 & 0.97 & 1.002 & 8.3 & 0.3 & 95 & 1 \\
\hline & & \multicolumn{10}{|c|}{ Slate S } \\
\hline 0 & 50 & 1.1 & 0.96 & 0.57 & 4.92 & 0.89 & 1.5 & 25.3 & 4.51 & 48 & 0.99 \\
\hline 30 & 15 & 0.93 & 0.96 & 0.69 & 4.56 & 0.91 & 0.49 & 7.55 & 0.68 & 15 & 0.99 \\
\hline 90 & 65 & 0.9 & 0.96 & 0.72 & 3.83 & 0.7 & 1.09 & 27.04 & 7.05 & 65.4 & 0.99 \\
\hline
\end{tabular}

As given in Table 4, the proposed modified criterion is able to properly predict the triaxial test data with the correlation coefficient of more than 0.98 . Since failure did not occur at the $\beta=0$ and $\beta=90$, in which the behavior of intact anisotropic rock is similar to intact isotropic rock (Jaeger, 1960), values of parameter $\alpha$ at these directions are near to one and the new modified criterion decreases to its original form for the intact isotropic rock.

As it was mentioned previously, to determine the ability of each criterion in predicting the strength of anisotropic rocks, RMSE was taken into account. For the aim of present study, RMSE can be calculated as

$$
\text { RMSE }=\sqrt{\frac{\sum_{i=1}^{n}\left(\sigma_{i}^{t}-\sigma_{i}^{p}\right)}{n}}
$$

Where $\sigma_{i}^{t}$ and $\sigma_{i}^{p}$ are the tested and predicted values of $\sigma_{1}$ for the $i^{\text {th }}$ data, respectively and $n$ is the number of data points. Figure 7 compares the RMSE values of the new modified criterion with the other two ones. 


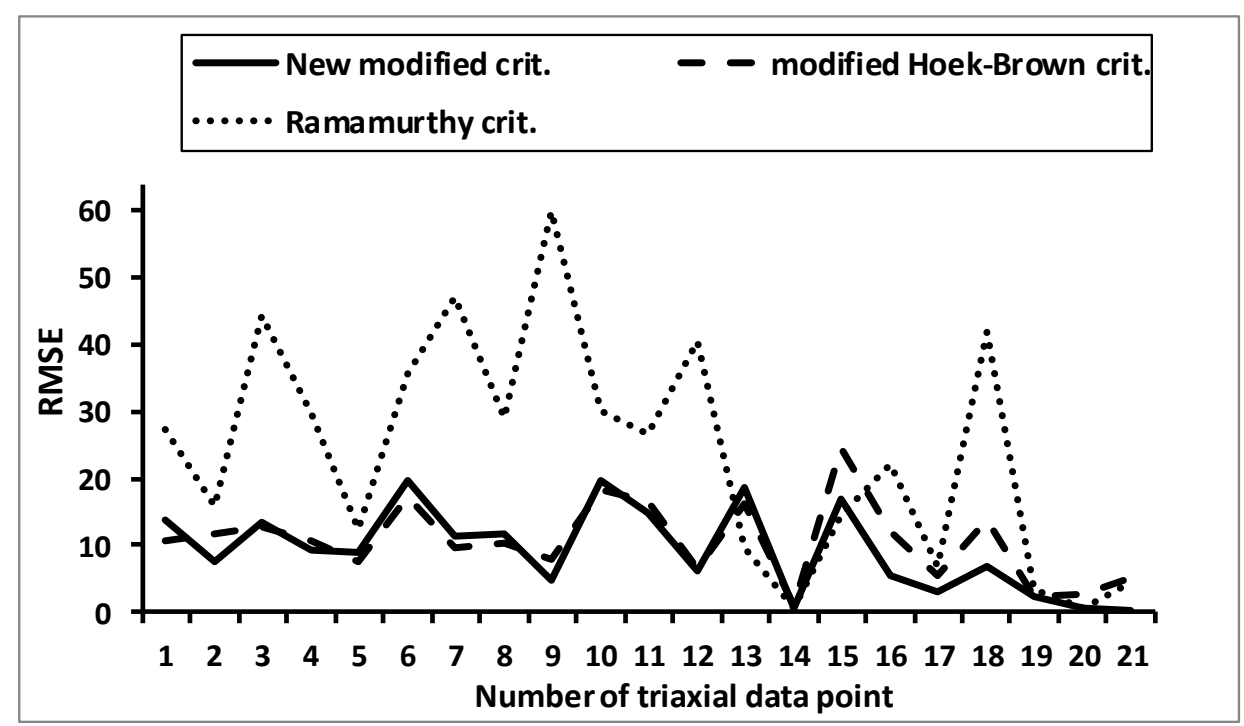

Fig. 7 RMSE values calculated by fitting the new modified, modified Hook-Brown and Ramamurthy criteria to the triaxial data

As it is depicted in Fig. 7, the modified criterion shows reasonable RMSE value near to modified Hoek-Brown, which is lower than that of Ramamurthy criterion is. Hence, it can be concluded that highest correlation coefficient and lowest RMSE are associated with the modified criterion indicating its strength and robustness in predicting the behavior of the anisotropic rock. Furthermore, one additional way of assessing the accuracy of a criterion is measuring its ability to predict the rock uniaxial compressive strength. According to Table 4 given, the predicted uniaxial strength of proposed criterion, $\sigma_{c-p r}$, is quite close to that of the laboratory test, $\sigma_{c \beta-l a b}$. Thus, the modified criterion can also predict the strength of intact anisotropic rock considerably better than the others can.

\section{Strength reduction parameter of the modified criterion}

The results obtained from fitting the new modified on the triaxial data have shown that parameter $\alpha$ (i.e. the one presented in Table 4 as the strength anisotropy parameter) has a consistent relationship with $\beta$. It will be more obvious when we look at the value of $\alpha$ in $\beta=0$ and $\beta=90$ where parameter $\alpha$ is nearly equal to 1 and the modified criterion changes to its original form (Eq. 6) for intact isotropic rock. Figure 8 (a) and (b) shows the variation of parameter $\alpha$ with anisotropy orientation $\beta$ for slate $\mathrm{S}, \mathrm{G}, \mathrm{Z}$ and gneiss A, B, schist, respectively.

(a) 


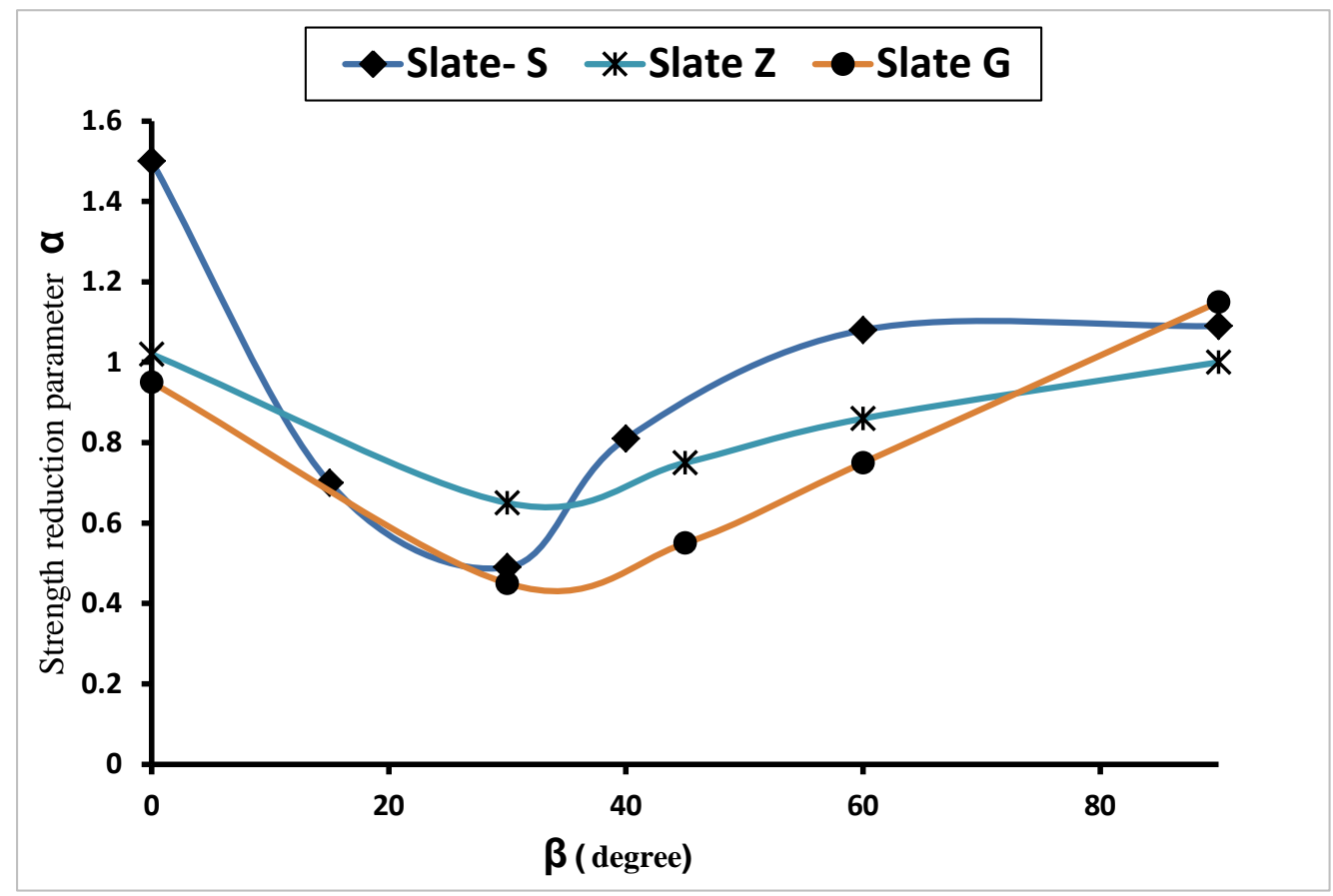

(b)

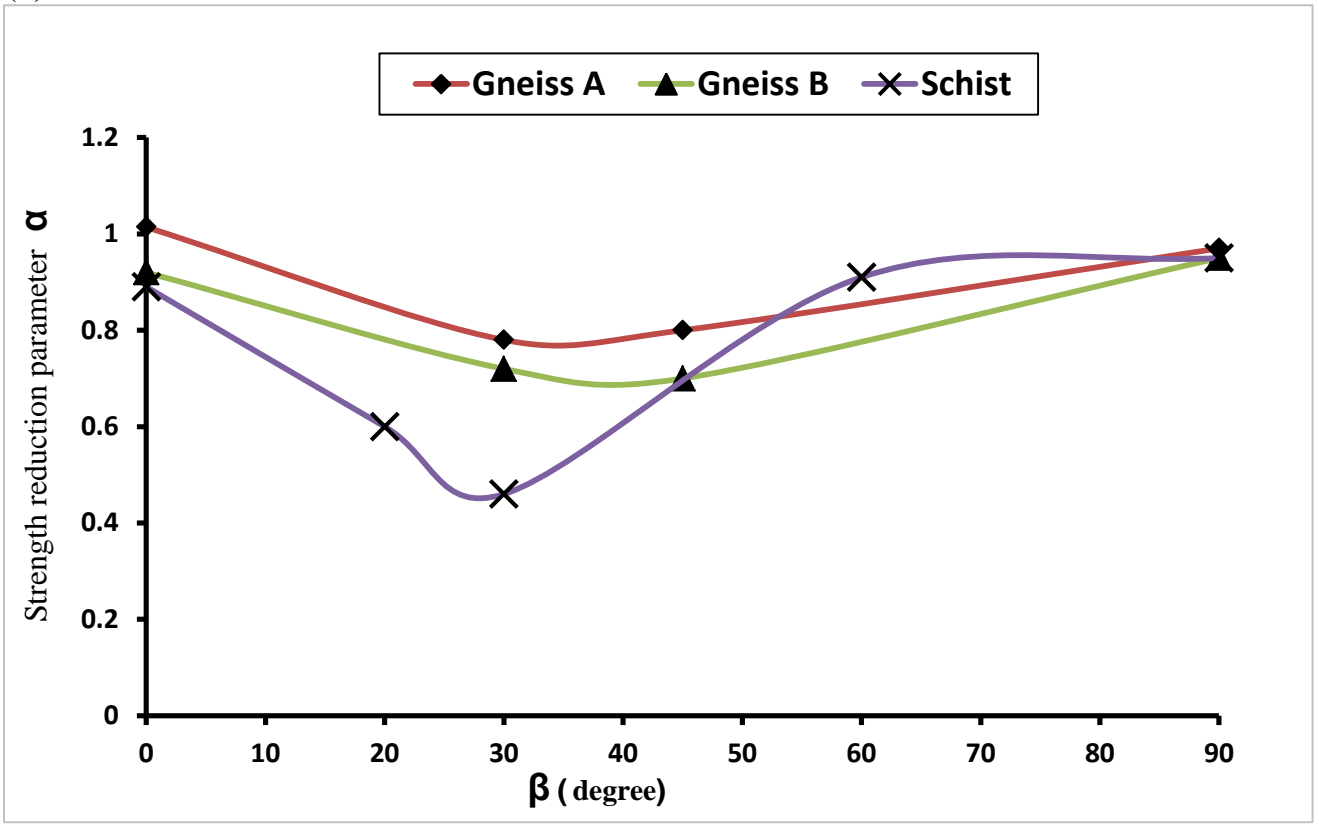

Fig. 8 The variation of parameter $\alpha$ with the anisotropy orientation $\beta$ for different rock types

As shown in Fig. 8 (a) and (b) the parameter, $\alpha$ decreases when the angle of anisotropy locates between $30-50^{\circ}$, introducing this parameter as a strength reduction parameter for anisotropic rocks. In addition, according to aforementioned definitions of previous sections, the ratio of $\alpha_{90} / \alpha_{\min }$ can be taken into account as the strength anisotropy effects. Figure 9 compares this ratio with $k_{90} / k_{\beta \min }$ and degree of strength anisotropy $R_{c}$ for different anisotropic rocks. 


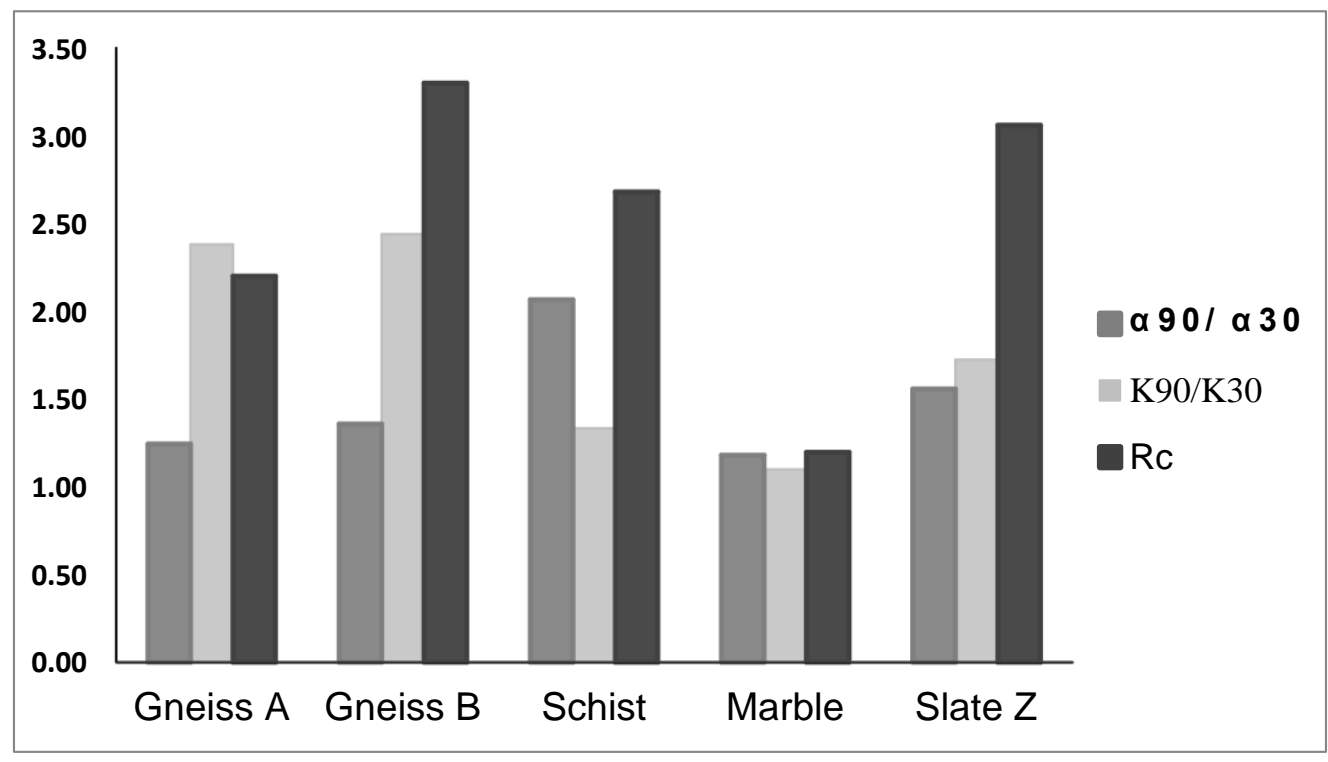

Fig. 9 Comparison of strength anisotropy parameters using the triaxial test criteria

Many scientific research works measured the degree of anisotropy of different rocks based on uniaxial compressive strength, tensile strength, point load index, Young's modulus, etc. (Ramamurthy, 1993; Amadei, 1996; Nasseri et. al. 2003). The achievements have shown that metamorphic rocks in terms of intensity in degree of anisotropy are classified as slate, schist, gneiss and marble. Regarding to Figure 9, the ratio of $\alpha_{90} / \alpha_{30}$ is able to rank the metamorphic rocks tested in similar way and, thus, it can be considered as strength anisotropy index of anisotropic rocks.

\section{Conclusions}

A study on the mechanical behavior of the anisotropic slate obtained from different districts is presented. A recently proposed rock failure criterion presented by Rafiai (2011) was modified to use for determining the strength of intact anisotropic rocks. Failure envelopes of the proposed criterion were compared to those of the modified Hoek-Brown and Ramamurthy criteria. The proposed modified criterion was tested for triaxial test data of the anisotropic intact rocks relative to the well-known modified Hoek-Brown criterion (Saroglou and Tsiambaos, 2008).

The proposed modified criterion gives a relatively higher correlation and lower root mean square error compared to those of the Ramamurthy criterion. It can predict uniaxial compressive strength of the intact anisotropic rock, accurately. The parameter $\alpha$ involved in the proposed modified criterion shows a usually U-shaped relationship with orientation of anisotropy. Hence, it can be considered as the strength reduction parameter. The proposed modified criterion precisely represents the behavior of intact anisotropic rocks as its original failure criterion introduced by Rafiai (2011), which can predict the behavior of intact isotropic rocks accurately. However, it limited to the strength prediction for intact anisotropic rocks and triaxial testing conditions. Further study is needed to extend the modified criterion for anisotropic rock masses and also poly-axial testing condition with emphasize on the effect of intermediate principal stress. 


\section{References}

Al-Harthi AA (1998) Effect of planar structures on the anisotropy of Ranyah sandstone, Saudi Arabia. Eng Geol., 50:49-57.

Allirote D, Boehler JP (1970) Evaluation of mechanical properties of a stratified rock under confining pressure. Proceedings of the Fourth Congress on I.S.R.M., Montreux 1:15-22.

Amadei B, Savage WZ. (1989). Anisotropic nature of jointed rock mass strength. J Eng Mech Div ASCE; 115(3):525-42

Amadei, B.1996. "Importance of anisotropy when estimation and measuring in situ stresses in rock”. Int. J. Rock Mech. \& Min. Sci. Geo. Abs.;33(3):293-326.

Attewell P, Sandford M (1974) Intrinsic shear strength of a brittle, anisotropic rock-I. Experimental and mechanical interpretation. Int J Rock Mech Min Sci Geomech Abstr, 11:423-30.

Barla G, Goffi L (1974) Direct tensile testing of anisotropic rocks, In Proceedings of the 3rd Congress of the International Society for Rock Mechanics, Denver, Colorado, USA, 1974, Vol. II, Part A, 93-98. Washington DC: National Academy of Sciences.

Barla G, Innaurato, N (1973) Indirect Tensile Testing of Anisotropic Rocks. Rock Mechanics 5: 215-230.

Chen CS, Hsu SC (2001) Measurement of Indirect Tensile Strength of Anisotropic Rocks by the Ring Test. Rock Mech Rock Eng, 34 (4): 293-321.

Colak K, Unlu T (2004) Effect of transverse anisotropy on the Hoek-Brown strength parameter ' $\mathrm{m}_{\mathrm{i}}$ ' for intact rocks. Int J Rock Mech Min Sci, 41:1045-1052.

Darvishzadeh A (1991) Geology of Iran, 3rd edition, Tehran (In Farsi).

Donath F (1964) Strength variation and deformational behavior in anisotropic rock. In: Judd WR, editor. State of stress in the Earth's crust. New York: Elsevier, p. 281-98.

Donath FA (1961) Experimental study of shear failure in anisotropic rock. Geol Soc Am Bull, 72:985-90.

Elmo D, Stead D (2010) An Integrated Numerical Modelling-Discrete Fracture Network Approach Applied to the Characterization of Rock Mass Strength of Naturally Fractured Pillars. Rock Mech. Rock Eng., 43:3-19.

Hoek E (1964) Fracture of anisotropic rock. J S Afr Inst Min Metall, 64:501-18.

Hoek E, (1990) Estimating Mohr-Coulomb friction and cohesion values from the HoekBrown failure criterion, Int J Rock Mech Min Sci., 27:227-229.

Hoek E, Brown ET (1980) Underground excavations in rock. London: Institution of Mining and Metallurgy.

Horino FG, Ellickson ML (1970) A method of estimating strength of rock containing planes of weakness. Report of investigation 7449, US Bureau of Mines.

Hudson JA, Harisson JP (2000) Engineering rock mechanics: An introduction to the principals. Elsevier, London, 1:163- 172.

ISRM, (2007) The Complete ISRM Suggested Methods for Rock Characterization, Testing and Monitoring: 1974-2006. R. Ulusay and J.A. Hudson (eds.), Suggested Methods Prepared by the Commission on Testing Methods, International Society for Rock Mechanics, Compilation Arranged by the ISRM Turkish National Group, Ankara, Turkey, 628 p. Jaeger JC (1960) Shear failure of anisotropic rock. Geol Mag, 97: 65-72. 
Jaeger JC, Cook NGW, Zimmerman RW (2007) Fundamentals of rock mechanics. $4^{\text {th }}$ edition, London: Blackwell publishing.

Karakul H, Ulusay R, Isik NS (2010) Empirical models and numerical analysis for assessing strength anisotropy based on block punch index and uniaxial compression tests. Int J Rock Mech Min Sci, 47 (4): 657-665.

Kwasniewski M. (1993). Mechanical behavior of anisotropic rocks. In: Hudson JA, editor. Comprehensive rock engineering, vol. 1. Oxford: Pergamon: 285-312.

Lo TW, Coyner KB, Toksoz MN (1986) Experimental determination of elastic anisotropy of Berea Sandstone, Chicopee shale, and Chelmsford granite. Geophysics, 51:164-171.

Marinos P, Hoek E (2000) GSI: a geologically friendly tool for rock mass strength estimation. In: Proceedings of the GeoEng2000 conference, Melbourne, 2000. p. 1422-40.

Matlab software (2009) The language of technical computing. The Mathwork Inc.

McLamore R, Gray KE (1967). The mechanical behavior of anisotropic sedimentary rocks. Transition in American Society of Mechanical Engineering Series B: 62-76.

Nasseri MH, Rao K, Ramamurthy T (2003) Anisotropic strength and deformational behavior of Himalayan schists. Int J Rock Mech Min Sci, 40:3-23.

Nasseri MH, Rao KS, Ramamurthy T (1997) Failure mechanism in schistose rocks. Int J Rock Mech Min Sci., 34(3-4):219.

Nasseri MH, Seshagiri Rao K, Ramamurthy T (1996) Engineering geological and geotechnical responses of schistose rocks from dam project areas in India. Eng Geol, 44:183-201.

Nova R. (1980) The failure of transversely isotropic rocks in triaxial compression. Int J Rock Mech Min Sci, 17:325-32.

Paterson MS, Wong TF (2005) Experimental rock deformation - the brittle field. Springer verlog, Berlin Heidelberg.

Pomeroy CD, Hobbs DW, Mahmoud A (1971) The effect of weakness plane orientation on the fracture of Barnsley hard coal by triaxial compression. Int J Rock Mech Min Sci, 8:22738.

Rafiai H (2011) New empirical polyaxial criterion for rock strength. Int J Rock Mech Min Sci., 48: 922-931.

Ramamurthy T (1993) Strength, modulus responses of anisotropic rocks. In: Hudson JA, editor. Compressive rock engineering, Oxford: Pergamon, (1):313-29.

Ramamurthy T, Rao GV, Singh J (1988) A strength criterion for anisotropic rocks. Proceedings of the Fifth Australia-Newzeland Conference on Geomechanics, Sydney (1): 253-7.

Ramamurthy T, Venkatappa RG, Singh J (1993) Engineering behaviour of phyllites. Eng Geol, 33:209-25.

Rao KS, Rao GV, Ramamurthy T (1986) A strength criterion for anisotropic rocks. Ind Geotech J., 16(4):317-33.

Saeidi O, Elyasi, A (2012) A study on the anisotropic behavior of slate using a modified rock strength criterion: A case study from west basin of Iran. International mining congress \& Expo, Tehran.

Saroglou H, Marinos P, Tsiambaos G (2004) The anisotropic nature of selected metamorphic rocks from Greece. J S African Inst Min Metallurgy, 104(4): 215-222.

Saroglou H, Tsiambaos G (2008) A modified Hoek-Brown failure criterion for anisotropic intact rock. Int J Rock Mech Min Sci., 45: 223-234. 
Seyedi SJ, (2005) Determination of geomechanical properties of slate and its effect on stability of Zhave dam water tunnel. MSc. Thesis, Tarbiat Modares University, Tehran, Iran.

Singh M, Rao KS, Ramamurthy T (2002) Strength and deformational behavior of a jointed rock mass. Rock Mech Rock Eng., 35 (1): 45-64.

Taleghani AM (2002) Geomorphology of Iran, first publication, Tehran (In Farsi).

Wardle LJ, Gerrard (1972) The equivalent anisotropic properties of layered rock and soil masses. Rock Mech Rock Eng., 4(3): 155-175. 
Fig. 1 a) Angle of weakness plane measured from major loading direction, b) Variation of differential stress at failure condition of triaxial compression test with respect to plane of weakness (Paterson and Wong, 2005)

Fig. 2 Outcrop view of the slate at Golpayegan water tunnel used for obtaining slate G; (b) Blocks of a collapsed berm in Sardasht dam used for obtaining slate S; (c) Plan view of the right bank of Sardasht dam where stars shows the sampling locations for slate and dash lines shows the stabilizing berms; (d) Samples prepared from Zhaveh Dam site (slate Z)

Fig. 3 Thin sections of studied rock samples obtained perpendicular to the foliation, (a) slate G, (b) slate Z, (c) slate $\mathrm{S}$

Fig. 4 (a) The variation of uniaxial compressive strength with angle of anisotropy (from major loading direction); the variation of Young's modulus with angle of anisotropy (b) slate- S, (c) slate-Z, (d) slate-G

Fig. 5 Variation of $K_{\beta}$ parameter with anisotropy orientation for slate $\mathrm{S}, \mathrm{G}$ and Z

Fig. 6 Comparison of failure envelopes of the new modified, modified Hoek-Brown and Ramamurthy criteria for different anisotropic rocks

Fig. 7 RMSE values calculated by fitting the new modified, modified Hook-Brown and Ramamurthy criteria to the triaxial data

Fig. 8 The variation of parameter $\alpha$ with the anisotropy orientation $\beta$ for different rock types

Fig. 9 Comparison of strength anisotropy parameters using the triaxial test criteria

Table 1 Uniaxial and Triaxial data set of different anisotropic rocks used for present study

Table 2 Strength anisotropy parameters in uniaxial compression test for different rock types

Table 3 Cohesive strength and friction of the slate $\mathrm{G}, \mathrm{S}$ and $\mathrm{Z}$

Table 4 Obtained parameters from fitting the new modified, the modified Hoek-Brown and the Ramamurthy criteria for different anisotropic rock types 